\title{
REFLEXÕES JURÍDICAS SOBRE SUSTENTABILIDADE E ECOLOGIA INTEGRAL DIANTE DO IMPACTO DA UNIVERSALIZAÇÃO DAS TECNOLOGIAS DA INFORMAÇÃO E COMUNICAÇÃO (TICs) NA PRIVACIDADE E INTIMIDADE.
}

\author{
Murillo Cesar de Mello Brandão Filho ${ }^{1}$ \\ Patrícia Borba Vilar Guimarães ${ }^{2}$
}

RESUMO: Este artigo discorre sobre o impacto da universalização das tecnologias de comunicação e informação no direito fundamental da intimidade e privacidade da pessoa humana, refletindo sobre as consequências disso no meio ambiente no contexto da ecologia integral e sustentabilidade. A harmonia necessária à sustentabilidade do meio ambiente passa antes pelo equilíbrio e plenitude da personalidade do indivíduo? Para investigar essa questão, aplicou-se o método dedutivo com utilização da técnica da pesquisa bibliográfica e documental como referências para as análises feitas ao longo do estudo.

ABSTRACT: This article discusses the impact of the universalization of communication and information technologies on the fundamental right of privacy, reflecting on the consequences of this on the environment in the context of integral ecology and sustainability. Does the harmony necessary for the sustainability of the environment pass through the balance and fullness of the individual's personality? To investigate this issue, the deductive method was applied using the technique of bibliographic and documentary research as references for the analyzes made throughout the study.

\footnotetext{
${ }^{1}$ Mestrando em Direito pelo Programa de Pós-Graduação em Direito (PPGD) da Universidade Federal do Rio Grande do Norte - UFRN. Procurador Federal. Lattes: http://lattes.cnpq.br/4558790742669435. Orcid: https://orcid.org/0000-0002-5697-8580. E-mail: murillo.brandao@ufrn.edu.br

${ }^{2}$ Doutora em Recursos Naturais pela Universidade Federal de Campina Grande (UFCG). Mestre em Direito pela Universidade Federal do Rio Grande do Norte (UFRN). Advogada e Professora da Universidade Federal do Rio Grande do Norte (UFRN). Lattes: http://lattes.cnpq.br/3134219236556237. Orcid: https://orcid.org/0000-00019130-3901. E-mail: patriciaborb@gmail.com
} 
PALAVRAS-CHAVE: Privacidade. Sustentabilidade. Ecologia Integral. Tecnologia. Proteção de dados.

KEYWORDS: Privacy. Sustainability. Integral Ecology. Technology. Data protection.

\section{INTRODUÇÃO}

O objetivo do estudo é analisar o direito fundamental da pessoa humana à privacidade como possível elemento necessário à ecologia integral e à sustentabilidade no contexto da universalização do uso de tecnologias da informação e a busca pelo bem-estar social.

Para isso, apresentam-se os conceitos desses institutos e analisa-se uma possível interligação entre eles, abordando a natureza e a necessidade de proteção jurídica diante do impacto provocado por efeitos deletérios e indesejados da inovação tecnológica. O tema central é enfrentado, utilizando como recorte o delicado, e necessário, equilíbrio estreito que deve ser perseguido entre o avanço e a disseminação da inovação tecnológica com a tutela geral da pessoa humana e a natureza sustentável. Esse parece ser o único caminho possível para o bem-estar e preservação da atual e futuras gerações.

Nesse contexto, a Constituição Federal de 1988, a Lei Geral de Proteção de Dados Pessoais (LGPD - Lei $\left.{ }^{\circ} 13.709 / 2018\right)$, promulgada para proteger os direitos fundamentais de liberdade e de privacidade e a livre formação da personalidade de cada indivíduo, e o Marco Civil da Internet (Lei $\left.\mathrm{n}^{\circ} 12.965 / 2014\right)$, que estabelece princípios, garantias, direitos e deveres para o uso da Internet no Brasil, são utilizados como referenciais normativos da observação.

Por último, é abordado o recente julgamento do plenário do Supremo Tribunal Federal que, por ampla maioria de 10 votos, reconheceu a existência de um direito fundamental autônomo à proteção de dados pessoais ao referendar a Medida Cautelar nas Ações Diretas de Inconstitucionalidade $n^{\circ} 6387,6388,6389,6393,6390$, suspendendo a aplicação da Medida Provisória 954/2018, que obrigava as operadoras de telefonia a repassarem ao IBGE dados identificados de seus consumidores de telefonia móvel, celular e endereço.

O método aqui utilizado é o dedutivo através de pesquisa descritiva acerca do tema central, apresentando uma reflexão crítica ao final, que correlaciona fatos e fenômenos sociais, sem manipulá-los, capturando dados e informações, através da técnica da investigação bibliográfica de estudos, artigos científicos, relatórios, sítios eletrônicos informacionais, livros acadêmicos e decisões judiciais. 
Em síntese, a justificativa e a relevância da aplicação desse método no presente artigo está na busca de respostas à seguinte questão: Diante do impacto dos efeitos nocivos da inovação tecnológica, por que a privacidade e a intimidade das pessoas são essenciais ao meio ambiente sustentável e para a vida saudável dos indivíduos na casa comum?

\section{SUSTENTABILIDADE E ECOLOGIA INTEGRAL}

Natureza é vida. A harmonia necessária à sustentabilidade do meio ambiente passa pelo equilíbrio e plenitude da personalidade do indivíduo. O conceito de ecologia integral procura integrar as dimensões ambiental, humana, econômica, social, cultural e urbanismo (vida cotidiana) do viver. Essa escola de pensamento percebe revolucionariamente, e procura compreender, uma profunda interligação entre todos os elementos dos fenômenos da humanidade e da natureza. Cervi et al. (2017, p. 150) defendem que há duas categorias para apreender o conceito de ecologia integral: Explicação de fenômenos (análise) e Compreensão (hermenêutica). Ambas se complementam e são interdependentes no desafio de fazer ciência:

A expressão Ecologia Integral não é apenas um conceito analítico utilizável para fragmentar, dissociar, quantificar, calcular, para, daí, explicar fenômenos, sejam estes naturais ou humanos. Ecologia Integral é, também, uma categoria de compreensão. Tal significa dizer que não é suficiente, apenas, fazer ciência explicando fenômenos. Necessário se faz também compreendê-los. Nesse viés, a expressão Ecologia Integral, além de uma categoria analítica, é uma categoria hermenêutica que aponta, ao mesmo tempo, para duas direções interligadas e interdependentes: num sentido, a expressão aponta para uma consciência gnosiológica que se desperta a partir da análise que leva a verdades resultantes da explicação; pelo caminho analítico, as pessoas chegam ao conhecimento da lógica dos fenômenos; noutro sentido, a categoria Ecologia Integral aponta para uma consciência, não apenas de conhecimento, mas de internalização de um entendimento que poderá transformar e modificar valores, atitudes $e$ comportamentos de sujeitos; pelo caminho hermenêutico, as pessoas não permanecem apenas numa consciência gnosiológica, mas podem integrar uma consciência ético-moral.

As relações entre humanos e a natureza é entendida através da investigação de diversas interconexões complexas e profundas que existem nas mais variadas dimensões da vida. A interdependência sistêmica é o valor central dessa compreensão e o equilíbrio estreito entre essas 
variáveis é o horizonte a ser perseguido em busca do bem-estar dos humanos e da preservação da natureza.

Assim, a ecologia integral também procura obter respostas para a preservação da humanidade diante da massificação do uso da tecnologia provocada pela inovação e pelo novo paradigma de consumo descuidado e insaciável. Essa reflexão é tão desafiadora que provocou a mobilização de uma das instituições mais conservadoras da história, a igreja católica. O Papa Francisco publicou em 2015 a Carta Encíclica Laudato Si com o seguinte espírito de ideias: "pensar e discutir acerca das condições de vida e de sobrevivência de uma sociedade, com honestidade de pôr em questão modelos de desenvolvimento, produção e consumo" (PAPA, 2015)

A internalização de uma consciência responsável e a adoção de práticas de cuidado (para consigo e para com os outros) em relação à sustentabilidade da casa comum são reconhecidas como um caminho crítico alternativo à degradação e no sentido favorável à qualidade de vida integral. A vida não pode ser regulada pelo mercado, mas sim pelo equilíbrio.

Como seria possível construir a harmonia integral em tempos de tecnologia avassaladora? Analisando a natureza do valor cuidado no processo evolutivo da humanização, Cervi et al. (2017, p. 159) destacam a integração dessa dimensão ao desenvolvimento da consciência ético-moral das pessoas através de uma lenta e progressiva aprendizagem evolutiva ao longo de sucessivas gerações da espécie:

\footnotetext{
Tornar-se responsável e tornar-se cuidadoso possui uma conexão muito visível desde o horizonte do constituir-se humano. Cuidar, como já se observou anteriormente, inter-relaciona proteção, preocupação, aflição, como, também, comprometimento, compaixão e afeto (do verbo afetar).

A fase do cuidado, que ora está-se refletindo, é a fase da auto-observação e a da vigilância no sentido de observar que ser humano sou eu, que ser humano somos, o que estamos fazendo, quem nos fez o que somos e, ao mesmo tempo, é a fase de observar e vigiar os fenômenos naturais e humanos em suas mais variáveis dimensões, para não apenas refletir essas e outras questões, mas também para mudarmos no que necessário for. A fase do cuidado não é apenas uma fase de criar uma consciência racional, mas uma consciência de auto mudança, de transformação de si mesmo e, no sentido coletivo, de nós mesmos.
}

A dimensão de cuidado e o processo de desenvolvimento da consciência ética-moral parecem ser uma conexão possível e desejável entre a ecologia integral e o direito fundamental à privacidade tendo em vista que a intimidade consubstancia um espaço essencial para a lenta e 
permanente construção do indivíduo responsável através do seu amadurecimento pela reflexão interior. Perceber-se como ser único, singular, autônomo, senhor das suas escolhas, repleto de sentimentos e fragilidades em meio a um universo complexo e, por diversas vezes, incompreensível aos olhos do homo sapiens é algo libertador, harmonizador e caminho para a e evolução da espécie.

A intimidade é tão poderosa e transformadora que, para indivíduos imaturos, em algumas situações, pode ser considerada, de forma equivocada, como sufocante e aterrorizante. Saber lidar com suas próprias angústias e frustrações ou com seus desejos, motivações e limites é, sem dúvida, o caminho ao equilíbrio.

A privacidade não consubstancia um espaço de solidão ou isolamento social, mas sim um habitat de algo totalmente diverso e único: o da meditação. É a intimidade que possibilita a construção permanente da percepção que o indivíduo tem dele mesmo e a representação que se faz do outro nos espaços intersubjetivos.

Ela também constitui um espaço fundamental para a construção da ética pois pode representar um lugar de libertação de recorrências à autoridade, subjugações ou justificativas exteriores, do julgamento público, do olhar ou viés de terceiros, do livramento da imposição do politicamente correto. Na sua privacidade, não há nada além da percepção e capacidade de compreensão do indivíduo. É o universo onde o Ser (indivíduo) é elaborado e colocado em contraponto ao Dever Ser (coletividade). Ter o direito de ser deixado, de ser esquecido ou de ter os dados pessoais respeitados não pode ser tido como valorização do egocentrismo. Ao contrário, representa uma verdadeira necessidade social de um momento importante de solitude, reflexão, elaboração e construção interior.

Nada melhor representa essa visão do que a imagem bíblica do deserto atravessado por Jesus Cristo: isolamento silencioso por quarenta dias e noites, sob jejum e tentações, a mente envolvida por pensamentos muito profundos, idealizações e, ao final, redenção, construção, compreensão e evolução. O deserto é considerado um locus fora dos limites da sociedade. Um lugar vazio do outro, mas repleto do eu (do seu eu e de mais ninguém). A construção final do processo de desenvolvimento desse eu íntimo (personalidade) é tida como iluminação. Nesse sentido, Hansel (1987, p. 54) afirma que

O deserto ainda é o melhor lugar para treinar líderes servos porque é um ambiente de aprendizado não neutro que exige mudanças e promove a comunidade, a confiança e a interdependência. O deserto encoraja a integridade, 
nos lembra o que é verdadeiro e real e nos oferece uma oportunidade como nenhuma outra de encontrar Deus como Ele é sem distração.

Sem enfrentar esse deserto (desenvolvimento da personalidade) e diante da tentação de idolatrar o diabo (por exemplo, abrir mão da sua intimidade nas redes sociais) em troca de todos os reinos do mundo (quem sabe por uma falsa sensação de atenção e pertencimento), qual seria o resultado disso na lenta construção e aperfeiçoamento da personalidade e consciência ética-moral da pessoa humana?

O psiquiatra e psicoterapeuta suíço Carl Gustav Jung (2002, p. 150-152) enfrenta essa questão e afirma que a única coisa que distingue um homem de todos os homens é a sua designação. ${ }^{3}$ Essa conquista representa a maturidade do indivíduo e é fruto da educação voltada para a formação da personalidade. O indivíduo que compreende e segue sua designação atinge a totalidade psíquica, dotada de decisão, resistência e força.

Atingir a personalidade não é tarefa insignificante, mas o melhor desenvolvimento possível da totalidade de um indivíduo determinado. Não é possível calcular o número de condições que devem ser satisfeitas para se conseguir isso. Requer-se para tanto a vida inteira de uma pessoa, em todos os seus aspectos biológicos, sociais e psíquicos. Personalidade é a realização máxima da índole inata e específica de um ser vivo em particular. Personalidade é a obra a que se chega pela máxima coragem de viver, pela afirmação absoluta do ser individual, e pela adaptação, a mais perfeita possível, a tudo que existe de universal, e tudo isso aliado à máxima liberdade de decisão própria. Educar alguém para que seja assim não me parece coisa simples. Trata-se sem dúvida da maior tarefa que nosso tempo propôs a si mesmo no campo do espírito.

Para Jung (2002, p.152), a personalidade se desenvolve no decorrer da vida e exige ação por parte do indivíduo, porque, de forma intencional, voluntária e moral, ele precisa se separar da grande massa de pessoas (que é indeterminada e inconsciente) e, através da reflexão produzida pelo isolamento, escolher seus próprios caminhos. Trata-se de um preço elevado a se pagar por algo muito valioso, a "tal felicidade" da totalidade de um ser único que indica a "fidelidade à sua própria lei” como pessoa autônoma.

Destacar-se voluntariamente do coletivo, libertar-se e se livrar das convenções do grupo, ser o senhor consciente das suas próprias escolhas, para o fundador da psicologia analítica, é um

\footnotetext{
${ }^{3}$ No sentido de vocação feita pela voz que provém do interior da pessoa. Revela confiança em si, lealdade repleta de confiança. A fidelidade à sua própria lei significa confiar nessa lei, perseverar com lealdade e esperar com confiança.
} 
desafio para poucos haja vista que esse caminho precisa ser necessariamente considerado melhor pelo indivíduo, pois, do contrário, no lugar da própria personalidade, a pessoa seguirá o caminho das convenções coletivas de natureza moral, social, política, filosófica, religiosa, econômica e ambiental.

De outra forma, na hipótese de não conseguir evoluir e formar sua personalidade, Jung afirma que a voz interior do indivíduo é substituída pela voz do grupo social e de suas convenções. Ocorre que, dada a inconsciência própria, a massa coletiva é incapaz de tomar uma decisão essencialmente livre e responsável:

O fato de as convenções de algum modo sempre florescerem prova que a maioria esmagadora das pessoas não escolhe seu próprio caminho, mas a convenção; por isso não se desenvolve a si mesma, mas segue um método, que é algo de coletivo, em prejuízo de sua totalidade própria.

A vida psíquica e social dos homens que se encontram em uma etapa primitiva é exclusivamente a vida do grupo, ao mesmo tempo que o indivíduo permanece num alto grau de inconsciência; de modo análogo, o desenvolvimento histórico posterior é geralmente assunto da coletividade e assim continuará sendo por certo. Por isso acho que a convenção é uma necessidade coletiva. É um expediente e não um ideal, tanto do ponto de vista moral como religioso, pois a submissão a ela sempre significa renúncia da totalidade e fuga diante de suas próprias e últimas consequências.” (2002, p.154-155).

A vida criadora fica sempre acima da convenção. Por isso deve haver uma erupção destruidora das forças criativas, quando predominar unicamente a rotina da vida na forma de convenções tradicionais. Essa erupção é catastrófica apenas como um fenômeno da massa, e jamais para o indivíduo que se submete conscientemente a essas forças superiores e coloca sua capacidade a serviço delas. O mecanismo das convenções conserva os homens inconscientes, pois então podem, à semelhança de animais selvagens, fazer mudanças há muito conhecidas sem ser preciso tomar uma decisão consciente. Essa atuação não intencionada por parte das melhores convenções é inevitável, mas nem por isso deixa de ser um perigo terrivel. Tal como acontece com os animais, entre os homens que são mantidos inconscientes pela rotina também pode surgir o pânico, com todas as consequências imprevisíveis, se as novas circunstâncias não parecerem previstas pelas antigas convenções. 
A personalidade não deixa dominar-se pelo pânico dos que acordam, pois já superou o terror. Ela está sempre preparada para as mudanças da época; ela é lider, mesmo sem o saber e sem o querer.” (2002, p.159)

Na mesma medida em que alguém se torna infiel à sua própria lei e deixa de tornar-se personalidade, perde também o sentido de sua própria vida. Por sorte a natureza bondosa e indulgente não chega a propor à maioria das pessoas essa pergunta fatal a respeito do sentido da própria vida. E, se ninguém pergunta, também ninguém precisa dar resposta. (2002, p.163)

Faz sentido proteger o meio ambiente através do pleno desenvolvimento da personalidade humana? A reflexão é certeira: Sim! O desenvolvimento da personalidade equivale a um aumento da consciência responsável. Noutras palavras, não há responsabilidade possível sem a prévia e plena personalidade do indivíduo. A plenitude e o amadurecimento individual permitem a vida sustentável e harmônica em todas as dimensões.

Fundamentando a responsabilidade como consequência direta do desenvolvimento de uma consciência ético-moral, Hans Jonas, discípulo de Husserl e Heidegger, no ensaio de uma ética para uma civilização tecnológica, defende que a intelectualidade não é suficiente ao comprometimento e engajamento com qualquer causa. Diante do impacto de efeitos nocivos-colaterais do processo acelerado, profundo e descontrolado do avanço tecnológico na sociedade, Jonas (2006) defende que a preservação da essência humana só é possível através de uma nova e profunda ética da responsabilidade para consigo, para com as pessoas e para com a natureza. Imperativo ético geral esse que é fundado na compreensão da humildade necessária à utilização do poder que a inovação permitiu aos homens:

uma nova espécie de humildade - uma humildade não como a do passado, em decorrência da pequenez, mas em decorrência da excessiva grandeza do nosso poder, pois há um excesso do nosso poder de prever e sobre o nosso poder de conceder valor e julgar" (2006, p. 63). "aja de modo a que os efeitos da tua ação sejam compatíveis com a permanência de uma autêntica vida humana sobre a Terra (2006, p.47)

O modelo tecnocêntrico que a inovação e o mercado estão construindo no coração da civilização exige reação consciente dos humanos no sentido do desenvolvimento de uma forte ética de cuidado e precaução. Não se trata aqui de criticar ou desancar a tecnologia, muito pelo contrário, ela é fundamental ao processo civilizatório. A reflexão proposta é centrada no comportamento do homem, como pondera Heidegger (2002, p.30-31) “a ameaça que pesa sobre o homem não vem, 
em primeiro lugar, das máquinas e equipamentos técnicos, cuja ação pode ser eventualmente mortifera. A ameaça, propriamente dita, já atingiu a essência do homem”

A ética da responsabilidade torna a privacidade essencial para a elaboração de habilidosos atos de autopreservação, cuja finalidade é evitar seu oposto, ou seja, a morte. Quanto maior a liberdade maior deve ser a responsabilidade. Esse equilíbrio ético estreito pode ser a condição fundamental para o bem-estar e para a própria sobrevivência das espécies. Sustentabilidade é equilíbrio. O meio ambiente não é um depósito infinito de matérias-primas à disposição dos interesses do homem. A resposta política e jurídica a essa constatação já foi dada pelo ordenamento jurídico. O momento atual exige efetividade dessas normas.

A Constituição Federal de 1988 estabelece em seu artigo 225 que "Todos têm direito ao meio ambiente ecologicamente equilibrado, bem de uso comum do povo e essencial à sadia qualidade de vida, impondo-se ao Poder Público e à coletividade o dever de defendê-lo e preserválo para as presentes e futuras gerações". Trata-se de previsão expressa da sustentabilidade como princípio orientador do bem-estar da vida em sociedade no Brasil.

Nesse passo, Freitas (2019, p. 45) conceitua sustentabilidade, através de uma percepção pluridimensional: "Trata-se do princípio constitucional que determina, com eficácia direta e imediata, a responsabilidade do Estado e da sociedade pela concretização solidária do desenvolvimento material e imaterial, socialmente inclusivo, durável e equânime, ambientalmente limpo, inovador, ético e eficiente, no intuito de assegurar, preferencialmente de modo preventivo e precavido, no presente e no futuro, o direito ao bem-estar."

A eficiência (uso de meios idôneos), o ambiente saudável e probo (dimensão ética), a precaução (dever de evitar danos prováveis) e o bem-estar (qualidade de vida por meio de um desenvolvimento equilibrado e orgânico acima de necessidades materiais) servirão de vetoresvalores ao presente artigo ao examinar e refletir sobre a privacidade (proteção de dados pessoais) como elemento essencial à sustentabilidade digital.

Aquino (2017, p. 203) argumenta a necessidade de compreensão de uma nova vertente específica e integradora do conceito de sustentabilidade: a dimensão tecnológica:

Todo e qualquer incremento no estilo civilizacional causado pela racionalidade, inventividade e criatividade humana impacta, significativamente, as estruturas de poder, o desempenho e as características profissionais, o desenvolvimento da economia e das culturas. Modificam-se, ainda, as próprias relações humanas. Veja-se as novidades as quais favoreceram essas mudanças por meio das 
navegações, da criação de um sistema de correspondências, da invenção das redes sociais, entre outros.

No entanto, para fins de se determinar outra face da Sustentabilidade, Tecnologia não gozaria, como outras vertentes, de um estatuto ontológico próprio. O que significa essa expressão "estatuto ontológico próprio”? A dimensão tecnológica da Sustentabilidade deveria ser caracterizada como "ser próprio", independente de outras situações que a caracterizam, ou, ainda, que a definiria como "ser" diferentes de outros fenômenos humanos.

A partir dessa condição, verifica-se, minimamente, que a Tecnologia é, antes, expressão de duas faces constitutivas da Sustentabilidade: Economia, História e Cultura. Ambas indicam quais necessidades humanas, no decorrer do tempo, precisam ser reconhecidas, aprimoradas e satisfeitas no intuito de favorecer a amplitude de uma vida digna. Por esse motivo, a Tecnologia é, sim, expressão de Sustentabilidade, no entanto, não goza de um “estatuto ontológico próprio”.

É necessário, também, sinalizar que a Tecnologia evidencia nossos permanentes esforços de resolver as principais dúvidas e limites da condição e natureza humana. Essas atitudes sinalizam a busca pela articulação política, jurídica, cultural, econômica, entre outros, de convivência global pautada pela lógica do comum. Entretanto, essa situação nem sempre ocorrerá.

Pelo exposto, assim como as técnicas, métodos e substâncias que comportem risco para a vida, a qualidade de vida e o meio ambiente devem ter a produção, comercialização e o emprego regulados pelo poder público, na forma preconizada pela Carta Política no Inciso V do referido artigo 225, tem-se que o direito fundamental à intimidade das pessoas precisa ser valorizado, respeitado, defendido e preservado pela coletividade (dever cívico) e pelo Estado (incumbência constitucional).

\section{TECNOLOGIA E RESPONSABILIDADE}

Tecnologia é poder. A intervenção do ser humano sobre os fenômenos naturais por meio de aplicações tecnológicas atribui ao homem um poder imenso, quase divino, muito acima da sua capacidade de compreensão dos efeitos e das consequências desencadeadas. Não pela variável "homem" (que é limitada, por essência), mas sim pelas variáveis "tempo" e "natureza", ambas absolutas e não totalmente compreendidas. 
A inovação tecnológica no sentido de todo e qualquer desenvolvimento da racionalidade tem papel fundamental no aperfeiçoamento civilizatório humano. Quanto maior a tecnologia, maior parece ser a racionalidade. Porém, quanto maior a racionalidade mais responsável precisa ser o homem. O bem-estar da coletividade (qualidade de vida) também deveria estar diretamente vinculado a esse círculo virtuoso de desenvolvimento (tecnologia, racionalidade e responsabilidade). No entanto, por muitas vezes, isso não é observado na prática. Algo corrompe a lógica. O incremento de tecnologia e aperfeiçoamento racional são percebidos apenas em benefício de parte da sociedade.

A responsabilidade chega a ser ainda menos verificada de forma disseminada, a tão desejada universalização de qualidade da vida (bem-estar) não se concretiza para toda a coletividade, a desigualdade entre humanos se aprofunda e a natureza é degradada como consequência disso. O intrigante é que para existir um paradoxo nessa realidade: Ainda que apenas parcela da sociedade se beneficie de forma plena com os avanços da inventividade, o efeito deletério desse processo finda por ser distribuído indiscriminadamente por todos os estratos sociais, ou seja, o benefício direto da tecnologia serve apenas a alguns e o risco geral é distribuído para todos.

A irresponsabilidade (falta de cuidado) e a desigualdade (baixa qualidade de vida) entre humanos nesse processo parecem ser as mais graves consequências do rompimento do círculo de desenvolvimento lógico entre inovação e bem-estar. De 1969, ano da criação da ARPANET ${ }^{4}$ pelo Departamento de Defesa dos Estados Unidos, que é considerada a gênese da Internet, até os dias atuais, observa-se um verdadeiro crescimento exponencial do uso da tecnologia da informação, que possibilitou avanços importantes, mas igualmente a explosão e massificação do uso de redes sociais virtuais por pessoas de todas as idades e de todos os lugares do mundo, seja nas relações travadas entre usuários de Internet e o setor privado, seja nas relações travadas entre cidadãos e a administração pública.

Um efeito destrutivo presente nesse avanço cibernético é o forte impacto que as TICs podem ocasionar na privacidade das pessoas. Isso é percebido tanto na mudança comportamental das pessoas, tolerando e buscando voluntariamente uma verdadeira cultura de exposição da intimidade como também na coleta e tratamento de dados pessoais feita, na maior parte das vezes, de forma silenciosa e automatizada, com fins econômicos e políticos, por algoritmos de grandes corporações.

\footnotetext{
${ }^{4}$ Advanced Research Projects Agency's Network
} 
Qual a consequência disso para as atuais e futuras gerações e, acima de tudo, para o meio ambiente? Leff (2015, p. 404) explana criticamente sobre um futuro insustentável que poderá ocorrer se a humanidade insistir em seguir o caminho das falsas certezas sobre o desenvolvimento tecnológico sem a preservação do equilíbrio ambiental:

Se entendermos o problema da insustentabilidade da vida no planeta como sintoma de uma crise de civilização - dos fundamentos do projeto societário da modernidade -, será possível compreender que a construção do futuro (sustentável) não pode apoiar-se em falsas certezas sobre a eficácia do mercado e da tecnologia - nem sequer da ecologia - para encontrar o equilíbrio entre crescimento econômico e preservação ambiental. A encruzilhada em que o novo milênio abre seu caminho é um convite à reflexão filosófica, à produção teórica e ao julgamento crítico sobre os fundamentos da modernidade, que permita gerar estratégias conceituais e praxeológicas que orientem um processo de reconstrução social. A complexidade ambiental e os processos de autoorganização geram sinergias positivas que abrem o caminho para uma sociedade sustentável, fundada numa nova racionalidade

A reflexão fica mais crítica ainda quando se observa a velocidade do avanço tecnológico, especialmente no universo digital. As mudanças têm sido tão vertiginosas e impactantes que parece existir um certo atordoamento humano sobre a compreensão de riscos e consequências danosas para a sociedade, para a natureza e para o futuro. Qual o sentido de renunciar voluntariamente à privacidade e viver permanentemente em estado de exposição da privacidade? Examinando o dilema da tecnologia como um problema ético, Alencastro (2009) afirma que:

nem a natureza nem a natureza humana podem ser tomadas como dados últimos e imutáveis para, com base neles, erguer-se uma avaliação ética dos efeitos da ação tecnológica. A tendência utópica e o poder da tecnologia exigem escolhas no que antes eram especulações. A grandeza do poder tecnológico modificou totalmente a distância entre questões próximas e remotas, entre as esferas da prudência e da sabedoria. Exige-se, dessa forma, uma nova responsabilidade, coextensiva à escala da excessiva grandeza do poder humano, na qual, cada escolha imediata exija o conhecimento das suas consequências remotas.

O progresso tecnológico dotou o homem de poder de ação que ultrapassa, em muito, tudo o que poderia ter sido suposto anteriormente. $O$ aparecimento das novas tecnologias, propiciadoras de um crescimento brutal dos poderes humanos (de um homem que é ao mesmo tempo sujeito e objeto de suas próprias técnicas), fez surgir o receio das nefastas consequências dos grandes poderes tecnológicos 
em ação. Por essa razão, não há mais espaço para argumentações em torno da neutralidade da ciência e da técnica." (2009, p. 18)

“O poder tecnológico à disposição do ser humano é capaz de afetar a natureza e a qualidade de vida das gerações presentes e futuras, e se configura como um fator de risco grave e, historicamente, inusitado, o que obriga, certamente, que seja revisto o conceito de responsabilidade. Nesse ponto, qualquer fórum que se proponha a discutir a problemática ambiental deve considerar esse alto fator de periculosidade e risco.

\section{(...)}

As situações de riscos que envolvam um forte impacto social ou ambiental devem ser tratadas em uma condição que exija o máximo de bases razoáveis para se crer que não implicam efeitos negativos. Como ocorrem em um contexto de incertezas, visto que os efeitos da ação tecnológica são, em muitos casos, de difícil previsibilidade, torna-se necessária a adoção de princípios conservadores que levem em consideração todos esses aspectos. Dois pontos merecem destaque:

1. Muitas vezes é impossível - em face dos conhecimentos científicos disponíveis - prever os perigos advindos da criação de um produto e (ou) processo. Nesse contexto, as decisões são feitas sempre em função dos conhecimentos do momento, o que as torna virtualmente arriscadas;

2. As responsabilidades dos desenvolvedores de novas tecnologias devem se estender aos domínios ulteriores (e que ainda não são previsíveis). É uma perspectiva preocupante, pois remete as inovações a um domínio espaço-temporal fora da previsibilidade usual." (2009, p. 24)

É relevante contextualizar aqui. Em relação à disseminação do uso de tecnologia da informação no Brasil, a pesquisa "TIC Domicílios” de $2018^{5}$ do Centro Regional de Estudos para o Desenvolvimento da Sociedade da Informação (Cetic.br) ${ }^{6}$, informa que cerca de 126 milhões de pessoas usaram a Internet regularmente em 2018, o que representa 67\% dos domicílios (46,5 milhões) com acesso à rede. Entrevistando domiciliares face a face por meio de tablets, esse estudo mediu o acesso às TIC`s (Tecnologias de Informação e Comunicação) nos domicílios brasileiros e

\footnotetext{
${ }^{5} \mathrm{~A}$ pesquisa TIC Domicílios é realizada anualmente desde 2005 com o objetivo de mapear o acesso à infraestrutura TIC nos domicílios urbanos e rurais do país e as formas de uso destas tecnologias por indivíduos de 10 anos de idade ou mais. A partir de 2013 a TIC Domicílios também incorporou em seu escopo a TIC Crianças, que investiga o uso de TIC entre indivíduos de 5 a 9 anos, e era realizada separadamente desde 2009. Os dados mais atuais no momento são os de 2018. Fonte: https://www.cetic.br/pesquisa/domicilios/

${ }^{6}$ O Cetic.br é um departamento do Núcleo de Informação e Coordenação do Ponto BR (Nic.br), que implementa as decisões e projetos do Comitê Gestor da Internet do Brasil (Cgi.br)
} 
seu uso pela população entre outubro de 2018 e março de 2019, perfazendo uma amostra de 23.508 residências em 350 municípios de todo país: 96\% têm acesso à TV, 93\% a telefones celulares e 19\% a computadores de mesa.

O crescente e disseminado uso da tecnologia digital cria desafios complexos à preservação de direitos fundamentais e à sustentabilidade. A reflexão sobre o impacto decorrente do uso nocivo de TICs abrange desde preocupações com a privacidade e o possível uso indevido de dados pessoais, passando por riscos gerados por crimes cibernéticos ou operações de vigilância/inteligência descontroladas e chega até o esgarçamento do meio ambiente provocado por práticas sociais insustentáveis.

Demonstração desse estado de coisas é a recente pesquisa "Microdados TIC Kids Online Brasil - 2019 - Pais e responsáveis"”, publicada em 23/06/2020 também pelo Cetic.br, que procurou compreender de que maneira a população de 9 a 17 anos de idade (crianças e adolescentes) e seus pais/responsáveis, residentes em domicílios particulares permanentes no Brasil, utiliza a Internet e como lida com os riscos e as oportunidades decorrentes desse uso. Os indicadores apresentados na pesquisa chamam bastante atenção: 1) Em relação ao acesso à Internet por telefone celular, 93\% das crianças e adolescentes responderam que SIM; 2) 58\% das crianças e adolescentes relataram que acessam à Internet exclusivamente pelo celular; 3) Sobre riscos, danos e conteúdos sensíveis, $22 \%$ assistiram a cenas de violência ou com muito sangue, $15 \%$ acessaram formas de cometer suicídio, $12 \%$ a formas de machucar a si mesmo, $10 \%$ a experiências ou uso de drogas e $15 \%$ acessaram conteúdo sexual.

Como se constata do resultado dessas pesquisas, a universalização da tecnologia digital está provocando para a maior parte da população uma nova percepção sobre o que seria vida privada, privacidade e intimidade, e erodindo, com isso, uma outrora sedimentada compreensão do sentido positivo e essencial da preservação da intimidade. As consequências podem ser graves. Costa Júnior (1995, p.22) fez o seguinte alerta, há 25 anos:

O processo de corrosão das fronteiras da intimidade, o devassamento da vida privada, tornou-se mais agudo e inquietante com o advento da era tecnológica. [...] A revolução tecnológica, sempre mais acentuadamente, ganha um dinamismo próprio, desprovido de diretrizes morais, conduzido por um "cientificismo" ao qual são estranhas e mesmo despreziveis quaisquer preocupações éticas, metafísicas, humanísticas.

\footnotetext{
${ }^{7}$ https://www.cetic.br/pt/pesquisa/kids-online/microdados/
} 
Sobre os riscos de precarização da intimidade e as consequências no desenvolvimento humano, é oportuno reverberar a advertência feita por Alencastro (2009, p. 17): “Os homens não são aliens acoplados a uma máquina sem vida, mas cidadãos de uma comunidade biótica abundante de vida. A existência humana está, portanto, intrinsecamente ligada à sobrevivência da natureza."

Uma outra pesquisa relevante sobre o tema é a "Quem defende seus dados?”, realizada anualmente pelo centro independente de pesquisa interdisciplinar - InternetLab, uma entidade sem fins lucrativos brasileira que "promove o debate acadêmico e a produção de conhecimento nas áreas

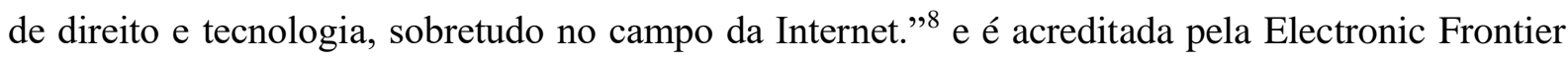
Foundation - $\mathrm{EFF}^{9}$, uma organização não-governamental americana fundada em 1990 que é pioneira na defesa de direitos digitais e lidera o projeto Who Has Your Back ${ }^{10}$

O método utilizado na pesquisa do ano de 2019 pelo InternetLab foi o seguinte: O projeto avaliou novamente empresas que já tinham sofrido sua análise em 2017, à época escolhidas por possuírem ao menos $1 \%$ do total de acessos à Internet no Brasil, segundo os dados divulgados pela Agência Nacional de Telecomunicações em maio de 2017. Após isso, foram elaboradas categorias e fixados parâmetros de avaliação capazes de mensurar 1) o comprometimento público com a obediência à lei; 2) a adoção de práticas e posturas pró-usuário; e 3) a transparência sobre as práticas e políticas. O resultado consolidou dados disponíveis até 10/06/2019 e, por fim, estabeleceu notas para os padrões de desempenho das empresas avaliadas.

Os resultados foram críticos. Nenhuma empresa conseguiu ser classificada com avaliações razoáveis no conjunto parâmetros sobre transparência e adoção de boas práticas em matéria de privacidade e proteção.

A importância do pensar reflexivo do presente artigo sobre o impacto do uso de TICs reside no fato de que um ataque à privacidade é uma agressão ao universo mais íntimo do indivíduo. Violar esse espaço fundamental de desenvolvimento, formação e afirmação da personalidade humana é, por consequência direta, inviabilizar a própria construção de uma sociedade equilibrada, porque é na intimidade livre e segura do ser humano que sua plenitude é gestada. Sem o indivíduo equilibrado não é possível conceber um meio ambiente sustentável. Logo, a privacidade apresentase como um dos pilares fundamentais à ecologia integral.

\footnotetext{
${ }^{8}$ http://quemdefendeseusdados.org.br/pt/ Acesso em 21.08.2020

${ }^{9}$ https://www.eff.org/ Acesso em 21.08.2020

${ }^{10}$ Em tradução livre, Quem Defende Seus Dados?
} 


\section{DIREITO, PERSONALIDADE E PROTEÇÃO DE DADOS}

Privacidade é direito fundamental. Personalidade é Tao ${ }^{11}$. Direitos inatos, decorrentes da própria natureza como ser humano, universais e com força para assegurar os interesses existenciais, o desenvolvimento da personalidade e a dignidade de toda e qualquer pessoa natural. Essa é a essência do conteúdo do direito fundamental.

Por expressa previsão constitucional, a "dignidade da pessoa humana" é fundamento da República Federativa do Brasil (Art. $1^{\circ}$, III), que tem com o objetivo fundamental a "promoção do bem de todos, sem preconceitos de origem, raça, sexo, cor, idade e quaisquer outras formas de discriminação" (Art. $\left.3^{\circ}, \mathrm{IV}\right)$. Trata-se do pilar de sustentação da proteção da pessoa humana em todo o ordenamento jurídico brasileiro.

Esse conceito-vetor tem fundamento na Declaração Universal dos Direitos Humanos adotada pela Assembleia Geral das Nações Unidas em 1948 ao estabelecer que o direito à vida privada é um direito humano: "Ninguém será objeto de ingerências arbitrárias em sua vida privada, sua família, seu domicílio ou sua correspondência, nem de ataques a sua honra ou a sua reputação. Toda pessoa tem direito à proteção da lei contra tais ingerências ou ataques." (Art. 12) e, ainda, no Pacto Internacional dos Direitos Civis e Políticos, também adotado pela Assembleia Geral das Nações Unidas, consagra, a esse respeito, que "Ninguém será objeto de ingerências arbitrárias ou ilegais em sua vida privada, sua família, seu domicílio ou sua correspondência, nem de ataques ilegais à sua honra e reputação. 2. Toda pessoa tem direito à proteção da lei contra essas ingerências ou esses ataques." (Art. 17).

Sobre o tema, Pinto (1999, p. 151) leciona: "Da garantia da dignidade humana decorre, desde logo, um verdadeiro imperativo axiológico de toda ordem jurídica, o reconhecimento de personalidade jurídica a todos os seres humanos, acompanhado da previsão de instrumentos jurídicos destinados à defesa das refracções essenciais da personalidade humana, bem como a necessidade de proteção desses direitos por parte do Estado."

No Brasil, são invioláveis todos os direitos que decorrem desse valor central e máximo. Como expressão disso, a própria Constituição Federal determina duas regras gerais protetoras da

\footnotetext{
${ }^{11}$ Tao é o caminho. O conhecimento intuitivo da "vida" que não pode ser apreendido completamente - tão somente - como um conceito, mas pode ser conhecido, no entanto, através da experiência de vida real, cotidiana. Fonte: https://pt.wikipedia.org/wiki/Tao Acesso em 21.08.2020
} 
essência do indivíduo, que são 1) o respeito à privacidade e 2) a inviolabilidade da intimidade, da honra e da imagem porque tais regras são classificadas como direitos e garantias fundamentais no Art. $5^{\circ}$ da Carta Maior.

A razão disso está no fato de que, para além do direito ao nome, à imagem, à liberdade, à honra e, à integridade física e psíquica, as informações de cunho pessoal (aquelas relacionadas à qualquer pessoa natural identificada ou identificável) são integrantes de uma nova e autônoma espécie dos direitos da personalidade do indivíduo: Um conjunto de normas guardiãs dos aspectos corpóreos e incorpóreos que são constitutivos da sua identidade, essencialidade, dignidade e que projetam na globalização do mundo a dimensão única de uma pessoa humana.

São essas regras seminais que garantem aquilo que é determinante para diferenciar um ser de outro, o atributo próprio, particular, individual, característico e único de um ser, que o difere de todos os demais. Os direitos da personalidade garantem aquilo que faz com que uma essência humana se individualize e esteja presente no mundo coletivo e social.

Esses direitos formam o conjunto de características do próprio indivíduo e consistem na parte intrínseca e genuína da pessoa humana. Trata-se da proteção jurídica da subjetividade necessária à vida individual. Nesse entendimento, De Cupis (1961, p. 17) assevera que: "serve à denominação direitos de personalidade àqueles direitos essenciais por constituírem a 'medula' da personalidade humana"

Ao lado disso, na vivência da sua identidade, seja através de experiências reais ou virtuais, o ser humano é considerado, por excelência, um ser social. A sua esfera relacional com outros seres individuais (vida em sociedade) também é assegurada pelos direitos da personalidade na medida que possibilitam a livre conexão e relacionamento entre pessoas únicas e próprias nos limites das suas respectivas identidades e liberdades. Trata-se da proteção da intersubjetividade necessária à vida em sociedade.

Ainda que a vida em sociedade seja fundamental, certamente é na esfera íntima e privada que a pessoa humana tem a chance de refletir, questionar-se e analisar criticamente a sua concepção de vida para, posteriormente, ir ao público, discutir os mais diversos assuntos, posicionar-se, experienciar o diálogo e o relacionamento com outros indivíduos. Sem a segurança desse refúgio interior, o livre desenvolvimento da subjetividade estaria sujeito à incessante e impiedosa pressão social, diversas vezes preconceituosa, discriminatória e totalitária. Nesse sentido, Gonçalves e Martin (2012, p. 9) lecionam que: 
Evidencia-se que a personalidade humana, característica ínsita à própria natureza do homem, reativou a exigência da tutela de certos valores por meio do direito, vez que essenciais para a qualidade de vida de todos os indivíduos. Especialmente a tutela do direito à intimidade e à privacidade, sendo essenciais para o pleno desenvolvimento da personalidade, favorece a disposição numa esfera de proteção em face de interesses, relações e necessidades que se pretende guardar do conhecimento de terceiros, como expressão maior de sua dignidade.

Sem a proteção dos direitos da personalidade, a pessoa poderia ser facilmente esmagada, formatada, fragilizada, massificada, desumanizada e, com a perda do caráter humano, a própria democracia, a vida em sociedade e a natureza sucumbiriam. Nessa quadra, a proteção de dados pessoais tem grande importância para que o indivíduo se realize de forma plena e se relacione livremente em sociedade. Por isso, tais direitos possuem regramento específico nos artigos 11 a 21 do Código Civil (Lei n 10.406/2002) e, pela sua importância, são tidos como intransmissíveis, irrenunciáveis e autodeterminados, não podendo, regra geral e com exceção somente nos casos previstos em lei, o seu exercício sofrer limitação voluntária.

Os direitos da personalidade fazem parte de uma cláusula geral de proteção do ser humano. Por esse motivo, a vida privada da pessoa natural é inviolável, e o judiciário, a requerimento do interessado, adotará as providências necessárias para impedir ou fazer cessar ato contrário a esta norma. (CC, Art. 21). A natureza especial desses direitos é essencial ao livre desenvolvimento da personalidade da pessoa natural e o desenvolvimento da pessoa humana é condição fundamental para uma sociedade livre, justa e solidária. Pinto $(1999$, p. 152) atesta, nessa quadra, que: “ $A$ afirmação da liberdade de desenvolvimento da personalidade humana e o imperativo de promoção das condições possibilitadoras desse livre desenvolvimento constituem corolários do reconhecimento da dignidade da pessoa humana como valor no qual se baseia o Estado."

É no íntimo da sua consciência e na privacidade da sua vida que o indivíduo reflete sobre suas escolhas, suas percepções de fenômenos humanos e da natureza, assimila e internaliza suas experiências vividas. Lafer (1988, p. 267) explica que:

A esfera da intimidade, diz Hannah Arendt, é regida pelo princípio da exclusividade. Esse princípio não se confunde com o da diferenciação, que marca a diferença entre os indivíduos, própria da esfera privada, e que se opõe ao público enquanto espaço do coletivo. A intimidade é a esfera que comanda as escolhas pessoais e que não segue nenhum padrão objetivo. É exatamente a intimidade enquanto esfera do exclusivo que a autora sugere como limite ao direito à informação, através da ponderação de que o que constitui a vida íntima 
das pessoas não é de interesse público. A intimidade não exige publicidade, porque não envolve direito de terceiros. E por ser exclusiva, sente-se lesada quando é divulgada ou invadida sem autorização.

Em argumentação no mesmo sentido, Farias (2000, p.140) leciona que:

A intimidade, como exigência moral da personalidade para que em determinadas situações seja o indivíduo deixado em paz, constituindo um direito de controlar a indiscrição alheia nos assuntos privados que só a ele interessa, tem como um de seus fundamentos o princípio da exclusividade, formulado por Hannah Arendt com base em Kant. Esse princípio, visando a amparar a pessoa dos riscos oriundos da pressão social niveladora e da força do poder político, comporta essencialmente três exigências: "a solidão (donde o desejo de estar só), o segredo (donde a exigência de sigilo) e a autonomia (donde a liberdade de decidir sobre si mesmo como centro emanador de informações)

É relevante compreender que o conceito jurídico-político de privacidade evoluiu na mesma medida do desenvolvimento da tecnologia. A consolidação desse direito da personalidade partiu da compreensão seminal do direito à liberdade, autonomia individual e identidade pessoal, concebidos, no Século XVII por John Locke, no estado de natureza como garantias essenciais do indivíduo, em face do arbítrio do outro, para poder viver livremente.

Em seguida, observa-se a construção do direito de ser deixado em paz $^{12}$ ou de ser deixado só $^{13}$. Após, tem-se como marco a decisão do Tribunal Constitucional Federal Alemão que reconheceu, em 1983, alicerçado no direito geral da personalidade, o direito fundamental à autodeterminação sobre dados pessoais.

Hodiernamente, experimentam-se a teoria dos direitos fundamentais e a ideia de círculos (esferas) concêntricos de privacidade (classificados por grau de proteção em ordem decrescente) de Robert Alexy e a tutela geral da integridade e intimidade dos dados pessoais no universo virtual ${ }^{14}$.

Acerca do tema, Doneda (2006, p. 142) ensina que "a privacidade adota uma "posição de destaque na proteção da pessoa humana, não somente tomada como escudo contra o exterior, mas

\footnotetext{
12 É possível encontrar menção ao termo na obra do juiz Thomas Cooley, que em 1880 publicou uma obra sob o título de "A treatise on the law of torts".

${ }^{13}$ Considera-se como marco desse momento o artigo "The Right to Privacy", publicado em 1890 na Harvard Law Review por Samuel Warren e Louis Brandeis. Fonte: BRANDEIS, Louis / WAREN, Samuel, "The right to privacy", Harvard Law Review IV (1890).

${ }^{14}$ Exemplos disso são o Regulamento Geral europeu sobre a Proteção de Dados - GDPR e, no Brasil, a Lei Geral de Proteção de Dados Pessoais - LGPD.
} 
como elemento positivo, indutor da cidadania, da própria atividade política em sentido amplo e dos direitos de liberdade de uma forma geral". Já Schreiber (2011, p. 137-138) afirma que "Em uma sociedade caracterizada pelo constante intercâmbio de informações, o direito à privacidade deve se propor a algo mais que àquela ideia inicial, restrita à proteção da vida íntima. Deve abranger também o direito da pessoa humana de manter o controle sobre os seus dados pessoais."

Destarte, para se efetivar a proteção constitucional à privacidade no universo digital, a Lei no 12.965/2014, o Marco Civil da Internet, acompanhada de seu regulamento, Decreto no 8.771/2016, estabelecem princípios, garantias, direitos e deveres para o uso da Internet no Brasil. O acesso à internet é tido como essencial ao exercício da cidadania. Nesse diploma, a proteção da privacidade e a proteção dos dados pessoais, na forma da lei, são erigidos à condição de princípios fundamentais do uso da rede mundial de computadores no Brasil e a inviolabilidade da intimidade e da vida privada, sua proteção e indenização pelo dano material ou moral decorrente de sua violação são assegurados expressamente como direitos do usuário.

Nesse mesmo espírito, a Lei Geral de Proteção de Dados Pessoais (LGPD - Lei $\mathrm{n}^{\circ}$ 13.709/2018) foi promulgada para proteger os direitos fundamentais de liberdade e de privacidade e a livre formação da personalidade de cada indivíduo. A lei dispõe sobre o tratamento de dados pessoais, dispostos em meio físico ou digital, feito por pessoa física ou jurídica de direito público ou privado e engloba um amplo conjunto de operações efetuadas em meios manuais ou digitais.

O alicerce do ordenamento jurídico brasileiro para proteção de dados pessoais é a utilização de informações pessoais apenas mediante o consentimento do titular dos dados, ou seja, prévia, expressa e inequívoca autorização antes de qualquer tratamento ser iniciado feita pela pessoa natural a quem se referem os dados pessoais objeto de tratamento. O domínio e o controle dos dados são direitos do seu titular.

Toda pessoa natural tem assegurada a titularidade de seus dados pessoais e garantidos os direitos fundamentais de liberdade, de intimidade e de privacidade, nos termos da LGPD (Art. 17). O conceito de dado pessoal é um elemento central para a incidência dessa Lei. A norma dirige-se a todo e qualquer dado em que se denote o prolongamento de um ser humano, seja de forma imediata ou mediata com potencial ingerência na esfera de uma pessoa, como aqueles utilizados para formação do perfil comportamental de determinada pessoa natural identificada.

Com efeito, um dado que não apresente tal condição não poderá ser considerado como uma projeção da personalidade da pessoa humana por ausência de tal centro de imputação e, com 
isso, não haverá incidência da LGPD. Considera-se "tratamento de dados" qualquer atividade que utilize um dado pessoal na execução da sua operação, por exemplo, a coleta, produção, recepção, classificação, utilização, acesso, reprodução, transmissão, distribuição, processamento, arquivamento, armazenamento, eliminação, avaliação ou controle da informação, modificação, comunicação, transferência, difusão ou extração.

Acatando as premissas e valores-fonte de proteção da personalidade humana, a Lei Geral de Proteção de Dados Pessoais permitiu expressamente em seu artigo $7^{\circ}$, de forma excepcional, dez hipóteses de tratamento de dados, bem como estabeleceu os requisitos para execução de tal procedimento. São as chamadas bases legais de tratamento de dados pessoais. Não se trata aqui de violação às duas regras gerais do nosso ordenamento, privacidade e intimidade, que disciplinam o respeito aos dados pessoais, mas sim afirmação de direitos e garantias fundamentais através de 1) estabelecimento de finalidades, controles de exposição e disponibilidade de informações; 2) regulação de limites e 3) definição de salvaguardas e responsabilidades.

A regra é a autorização de tratamento de dados pessoais apenas na hipótese de consentimento do seu titular. O tratamento de informações sem consentimento do cidadão é medida excepcional e só é possível de ocorrer quando isso for indispensável para cumprir situações legais. Os casos de tratamento de dados previstos e permitidos pela LGPD não são amplos e absolutos, ao contrário, existem limites para essa operação que estão dados pela boa-fé e demais princípios previstos no Art. $6^{\circ}$ da mesma norma.

O princípio da finalidade exige que os propósitos do tratamento de dados sejam legítimos, específicos, explícitos e informados ao titular, sem possibilidade de tratamento posterior de forma incompatível com esses propósitos (art. $\left.6^{\circ}, \mathrm{I}\right)$. O consentimento deverá referir-se a finalidades determinadas, e as autorizações genéricas para o tratamento de dados pessoais serão consideradas nulas.

Em outras palavras para não restar dúvida: Inexiste um salvo-conduto para o tratamento amplo e ilimitado de dados realizado com assento em base legal do Art. $7^{\circ}$, mas, de forma obrigatória, ele só pode ser feito mediante finalidade e necessidade definidas, ser adequado, utilizar medidas técnicas necessárias para garantir a segurança do dado contra incidentes e estar pronto para, ao final, ser descartado. Tal comando é orientado pelo princípio da especificação dos propósitos. 
Por fim, afirmando a necessidade de tal proteção, o plenário do Supremo Tribunal Federal que, por ampla maioria de 10 votos, reconheceu a existência de um direito fundamental autônomo à proteção de dados pessoais ao referendar a Medida Cautelar nas Ações Diretas de Inconstitucionalidade n. 6387, 6388, 6389, 6393, 6390, suspendendo a aplicação da Medida Provisória 954/2018, que obrigava as operadoras de telefonia a repassarem ao IBGE dados identificados de seus consumidores de telefonia móvel, celular e endereço.

Trata-se de julgamento histórico pois a constitucionalização da proteção de dados como garantia fundamental permite o acionamento do controle de constitucionalidade em face dos riscos e ameaças do avanço cibernético. A Ministra Rosa Weber, relatora, foi contundente ao decidir:

A Constituição da República confere especial proteção à intimidade, à vida privada, à honra e à imagem das pessoas ao qualificá-las como invioláveis, enquanto direitos fundamentais da personalidade, assegurando indenização pelo dano material ou moral decorrente de sua violação (art. $\left.5^{\circ}, X\right)$. O assim chamado direito à privacidade (right to privacy) e os seus consectários direitos à intimidade, à honra e à imagem emanam do reconhecimento de que a personalidade individual merece ser protegida em todas as suas manifestações.(...) No clássico artigo The Right to Privacy, escrito a quatro mãos pelos juízes da Suprema Corte dos Estados Unidos Samuel D. Warren e Louis D. Brandeis, já se reconhecia que as mudanças políticas, sociais e econômicas demandam incessantemente o reconhecimento de novos direitos, razão pela qual necessário, de tempos em tempos, redefinir a exata natureza e extensão da proteção à privacidade do indivíduo. Independentemente do seu conteúdo, mutável com a evolução tecnológica e social, no entanto, permanece como denominador comum da privacidade e da autodeterminação o entendimento de que a privacidade somente pode ceder diante de justificativa consistente $e$ legítima.

\section{CONSIDERAÇÕES FINAIS}

A inovação tecnológica é uma das causas do aperfeiçoamento civilizatório humano. Sua presença no desenvolvimento da racionalidade e qualidade de vida se mostra essencial. A ciência e o conhecimento objetivo devem ser valorizados e buscados sempre.

No entanto, há efeitos destrutivos colaterais nesse processo e eles precisam ser mitigados. $\mathrm{O}$ avanço e a disseminação da tecnologia não podem provocar a degradação da natureza ou a 
desumanização e até mesmo a extinção da espécie humana. A sustentabilidade do meio ambiente a preservação de todos os recursos e variáveis da natureza é condição sine qua non para o bem-estar e sobrevivência da atual e futuras gerações de humanos.

Por outro lado, a busca pela preservação da sustentabilidade não pode ser uma utopia ou se transformar em um vetor paralisante do desenvolvimento humano. No mesmo sentido, o indivíduo não pode ser compreendido como dono ou legítimo senhor da natureza e não está livre para esgarçar irresponsavelmente os recursos naturais na tentativa de satisfazer um consumo insaciável.

Equilíbrio estreito entre direito fundamental, inovação tecnológica, meio ambiente sustentável e o cuidado responsável com a casa comum parece ser o caminho possível para a universalização do bem-estar e preservação da natureza, da vida saudável e bem-estar da atual e futuras gerações.

A construção desse caminho da responsabilidade passa necessariamente pela preservação dos mecanismos ligados ao processo de aprendizagem evolutivo da consciência ética-moral da pessoa humana e, nesse contexto, a privacidade é o meio vital à garantia da intimidade necessária à reflexão e elaboração da personalidade crítica do indivíduo.

\section{REFERÊNCIAS}

ALENCASTRO, Mario Sergio. Hans Jonas e a proposta de uma ética para a civilização tecnológica. Desenvolvimento e Meio Ambiente, UFPR, n. 19, p. 13-27, 2009.

ALEXY, Robert. Teoria dos Direitos Fundamentais. Tradução de Virgílio Afonso da Silva. São Paulo: Malheiros, 2008. Título original: Theorie der Grundrechte.

AQUINO, Sérgio Ricardo Fernandes de. (Contra o) eclipse da esperança [recurso eletrônico]: escritos sobre a(s) assimetria (s) entre direito e sustentabilidade. Itajaí: Univali, 2017. 237 p. Disponível em: http://www.univali.br/ppcj/ebook. Acesso em: 03 ago. 2020.

BRASIL. Constituição da República Federativa do Brasil de 1988. Disponível em: <http://www.planalto.gov.br/ccivil_03/constituicao/constituição.htm>. Acesso em: 22.08.2020. 
- Lei 12.965/2014. Marco Civil da Internet. Disponível em: <http://www.planalto.gov.br/ccivil_03/_ato2011-2014/2014/lei/l12965.htm>. Acesso em: 22.08.2020.

. Lei 13.709/2018. Lei Geral de Proteção de Dados Pessoais. Disponível em: < http://www.planalto.gov.br/ccivil_03/_ato2015-2018/2018/lei/L13709.htm>. Acesso em: 22.08.2020.

- Supremo Tribunal Federal. ADI 6387 MC. Disponível em: <https://portal.stf.jus.br/processos/detalhe.asp?incidente=5895165> Acesso em: 22.08.2020.

CERVI, Jacson Roberto et al. O CUIDADO E A ECOLOGIA INTEGRAL. Direitos Culturais, Santo Ângelo, v. 12, n. 27, p. 149-172, 2017.

COSTA JÚNIOR, Paulo José da. O direito de estar só: tutela penal da intimidade. São Paulo, SP: Revista dos Tribunais, 1995.

DE CUPIS, Adriano. Os direitos da personalidade. Tradução Adriano Vera Jardim e Antônio Miguel Caeiro. Lisboa: Livraria Morais, 1961.

DONEDA, Danilo. Da privacidade à proteção de dados pessoais. Rio de Janeiro, RJ: Renovar, 2006. FARIAS, Edilsom Pereira de. Colisão de direitos: a honra, a intimidade, a vida privada e a imagem versus a liberdade de expressão e informação. 2. ed. Porto Alegre, RS: Sérgio Antonio Fabris, 2000. FREITAS, Juarez. Sustentabilidade: direito ao futuro. 4. ed. Belo Horizonte: Fórum, 2019.

GONÇALVES, Ana Catarina Piffer; MARTIN, Andréia Garcia. Os direitos à intimidade e à privacidade sob a perspectiva processual: a tutela inibitória dos direitos de personalidade. Revista Jurídica Cesumar - Mestrado, Maringá, v. 12, n. 1, p. 205-235, 2012.

HANSEL, Tim. Holy Sweat. Texas: Ed. W Pub Group, 1987.

HEIDEGGER, M. A questão da técnica. In: Ensaios e conferências. Petrópolis, RJ: Vozes, 2002.

JONAS, Hans. O Princípio Responsabilidade: ensaio de uma ética para uma civilização tecnológica. Rio de Janeiro: PUC Rio, 2006. 
JUNG, Carl Gustav. O Desenvolvimento da Personalidade: tradução: frei Valdemar do Amaral. 8. ed. Petrópolis: Vozes, 2002. 224 p. Tradução: Frei Valdemar de Amaral.

LAFER, Celso. A reconstrução dos direitos humanos: um diálogo com o pensamento de Hannah Arendt. São Paulo, SP: Cia das Letras, 1988.

LEFF, Enrique. Saber ambiental: sustentabilidade, racionalidade, complexidade, poder. Tradução de Lúcia Mathilde Endlic Orth. 11. ed. Petrópolis, (RJ): Vozes, 2015.

LOCKE, John. Segundo tratado sobre o governo civil: ensaio sobre a origem, os limites e os fins verdadeiros do governo civil. 3. Ed. Tradução de Magda Lopes e Marisa Lobo da Costa. Petrópolis: Vozes, 2001.

MOTA PINTO, Paulo. O direito ao livre desenvolvimento da personalidade. Coimbra: Ed. Coimbra, 1999.

ORGANIZAÇÃO DAS NAÇÕES UNIDAS (ONU). Declaração Universal dos Direitos Humanos. Paris, 1948.

Disponível em:

<http://www.direitoshumanos.usp.br/index.php/Declara\%C3\%A7\%C3\%A3o-Universal-dos-

Direitos-Humanos/declaracao-universal-dos-direitos-humanos.html>. Acesso em: 22.08.2020.

. Pacto Internacional sobre Direitos Civis e Políticos, 1966. Disponível em: <http://www.planalto.gov.br/ccivil 03/decreto/1990-1994/d0592.htm>. Acesso em: 22.08.2020. PAPA Francisco. Carta Encíclica Laudato Si. Sobre o cuidado da casa Comum. Roma: Tipografia Vaticana, 2015, n. 138.

SCHREIBER, Anderson. Direitos da personalidade. São Paulo: Atlas, 2011. 